\title{
An Overview on the Spinning Triangle Based Modifications of Ring Frame to Reduce the Staple Yarn Hairiness
}

\author{
Md. Khalilur Rahman Khan', Hosne Ara Begum², Md. Razib Sheikh' \\ ${ }^{1}$ Department of Textile Engineering, Bangladesh University of Business and Technology, Dhaka, Bangladesh \\ ${ }^{2}$ Department of Yarn Engineering, Bangladesh University of Textiles, Dhaka, Bangladesh \\ Email:mkrkhan@outlook.com
}

How to cite this paper: Khan, Md.K.R., Begum, H.A. and Sheikh, Md.R. (2020) An Overview on the Spinning Triangle Based Modifications of Ring Frame to Reduce the Staple Yarn Hairiness. Journal of Textile Science and Technology, 6, 19-39. https://doi.org/10.4236/jtst.2020.61003

Received: October 7, 2019

Accepted: December 22, 2019

Published: December 25, 2019

Copyright $\odot 2020$ by author(s) and Scientific Research Publishing Inc. This work is licensed under the Creative Commons Attribution International License (CC BY 4.0).

http://creativecommons.org/licenses/by/4.0/

\begin{abstract}
Traditional ring spinning system is associated with the several limitations, one of which is yarn hairiness. The awareness has been vibrantly growing among the spinning mills for reducing staple yarn hairiness because of its detrimental effects on the subsequent processes (i.e., weaving, knitting, dyeing etc.) and the quality of resultant textile products. As a result, modified form of ring frame has attracted a lot of attention among the researchers for making yarn with the lower level of hairiness value. Besides the raw material parameters and some processing variables, spinning triangle (ST) is the most critical region that has decisive influence on the distribution of fiber tensions and their spatial orientations and shapes in staple yarn body. Thus, using appropriate methods to control the spinning triangle geometry actively has been a vital issue in the field of yarn hairiness reduction. In this paper, it is attempted to make an overview on the spinning triangle based modifications of ring frame that have been designed and destined to reduce hairiness. However, agent aided ring spinning system has also been briefly discussed in this paper as well.
\end{abstract}

\section{Keywords}

Ring Frame, Compact Spinning, Spinning Triangle, Yarn Hairiness

\section{Introduction}

Ring-spinning technology is the most widely accepted method for producing long and short staple spun yarn; it is capable of spinning nearly all sorts of natural and synthetic fibers types such as cotton, polyester etc. within a very wide 
count range [1]. However, the conventional ring spinning system is disadvantaged by several limitations, one of which is the poor integration of many fibers that protrude from the yarn surface causing yarn hairiness [2].

Yarn hairiness is an important determinant to be strictly assessed and controlled in textile processes since they affect many aspects of yarns and consequently of fabrics [3] [4]. Besides the fabric undesirable fuzzy and hazy appearance, yarn hairiness has significant effects on handle, thermal insulation, pilling performance and abrasion resistance. The warp yarn size uptake is directly related to the level of yarn hairiness [5]. Excess yarn hairiness leads to increased production of fly during knitting. In dyeing, yarn hairiness leads to a differential dyeing effect [6]. Lower level of yarn hairiness will ensure sharper and more attractive printing and will also reduce the disturbances during sewing operation.

However, in ring spinning system, at the exit from the front rollers there is always a triangular bundle of the fibers without twist, which is called the spinning triangle (ST). This ST is a critical region in staple yarn spinning. The dimensions of the ST and the distribution of fibers in it have a decisive influence on the alignment of fibers both at the surface and within the yarn [7]. In an ST, fibers are always subjected to uneven load because of their positioning and spinning tension as well. For example, the marginal fibers are prevented from being completely incorporated into the yarn body. As a result, along with the raw material parameters and some processing variables, the geometry of ST determines the yarn strength, torque, and hairiness.

Therefore using appropriate methods to control the spinning triangle geometry actively has been a vital issue in the field of research. However, in this paper, it is attempted to make an overview on the spinning triangle (ST) based modifications of ring frame that have been destined to reduce the staple yarn hairiness. Future researchers will be acquainted and enriched with this knowledge in the way of further modifications.

\section{Various Types of Modifications}

\subsection{Compact Spinning System}

The compact spinning system was originally designed to improve yarn hairiness [8]. This is a revolution in ring spinning and even at this point in time, one can categorically say that the future belongs to compact yarns [9]. However, the objective of every compact spinning system is: Elimination of the spinning triangle; Integration of protruding and non-parallel fiber ends; Peripheral fibers are integrated without over stretching; Controlled relaxing of the fibers [10]. The elimination of the spinning triangle (shown in Figure 1) is merely a consequence of this arrangement [11].

Major compact spinning frame manufactures includes Rieter (K 48), EliTe of Suessen, Impact FX (Air-Com-Tex) of Zinser, Toyota ${ }^{\circ}$ RX-240, RoCoS and Ro$\mathrm{VaC}$ of Rotorcraft etc. available for short and long staple spinning sector. Currently, there are two basic principles, aerodynamically and mechanical compact 


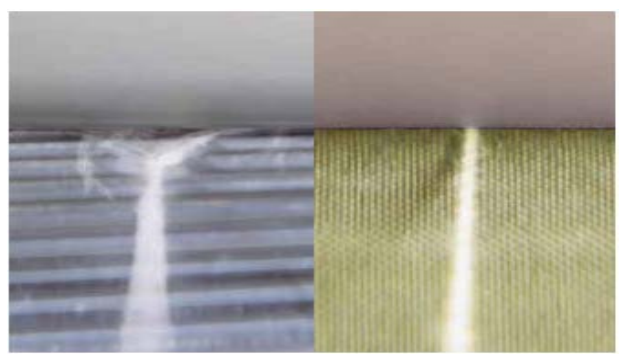

Figure 1. Spinning triangle of ring yarn versus compact yarn [11].

spinning system. Today, the available dominant compact spinning systems are the pneumatic compact spinning systems, which adopt perforated drum, perforated apron or lattice apron as condensing elements [12].

\subsubsection{Aerodynamically Compacting System}

Pneumatic compact spinning is the most widely used compact spinning method at present, in which the negative pressure airflow is used to condense the fiber bundle and decrease the spinning triangle [13]. Most of the pneumatic compacting systems are composed of perforated drums or lattice aprons over the openings of the suction slots. With the air flow, the fibers move sideways and they are consequently condensed. However the adaptation of this system to conventional ring spinning machine is very complex and expensive; also this method cause high additional energy consumption during spinning process [14].

1) Rieter Compact-Spinning Machine $K 48$ :

The fiber condensing zone immediately follows a 3-roller drafting system with double aprons. The bottom delivery roller of the drafting system is replaced by a positively driven perforated drum (sieve drum) with strip groove structure on the surface for this purpose (shown in Figure 2). A fixed suction system that is connected to the machine's central extraction unit generating a vacuum is fitted inside this perforated drum. This results in a current of air flowing from the outside to the inside of the drum. The fibers supplied from the delivery nip line of the drafting system are thus held firmly on the surface of the perforated drum and move with the circumferential speed of the drum. A subsequent, second top roller also presses on the drum. The area between the front nip and output nip is the condensing zone. An additional nip roller prevents the twist from being propagated into the condensing zone. The air current created by the vacuum generated in the perforated drum condenses laterally the fibers by means of aerodynamic forces after the main draft. The fibers are fully controlled all the way from the nipping line after the drafting zone to the spinning triangle (shown in Figure 3). The spinning triangle becomes so small as virtually to disappear. In the process, all the fibers from the remaining spinning triangle are collected and fully integrated in the yarn [15] [16]. The new air guide element (shown in Figure 4) Detect monitors the air flow to the individual spinning positions. If the under pressure reaches a limit value, a red marking on the air guide element indicates that the compacting unit must be checked. This feature prevents noncompacted yarn being produced [17]. 


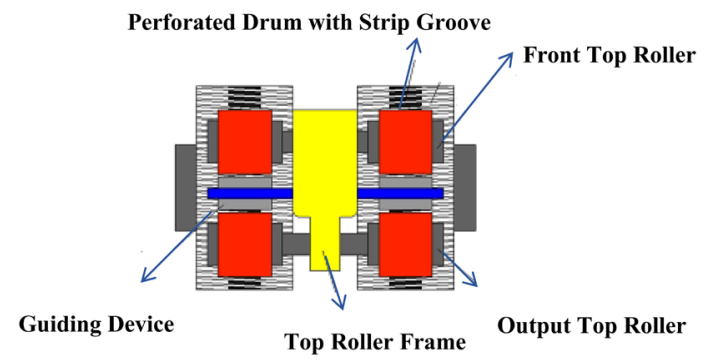

Figure 2. Structure of compacting zone at Rieter Compact K 48 [18].

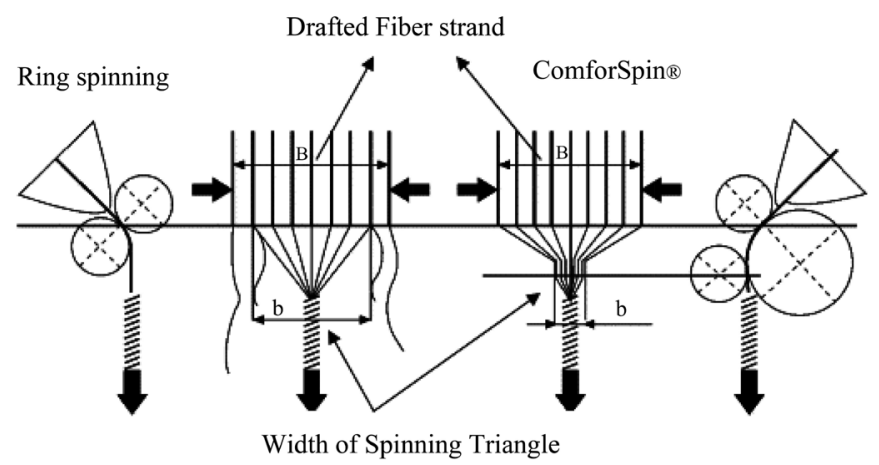

Figure 3. Spinning triangle of ring spinning and Rieter compact spinning system.

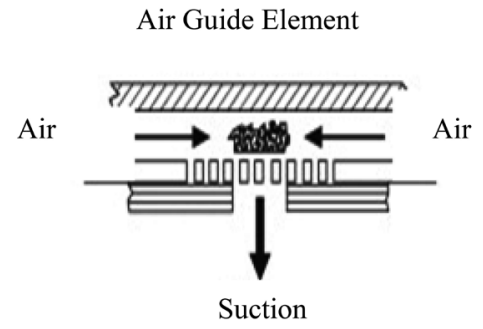

Figure 4. Air-Guide Element.

\section{2) $\mathrm{EliTe}^{\circ} \mathrm{CompactSet}$}

The system consists of a tubular profile subjected to negative pressure and closely embraced by a lattice apron (shown in Figure 5). The delivery top roller, fitted with rubber cots, presses the lattice apron against the hollow profile and drives the apron, at the same time forming the delivery nipping line. The tubular profile has a small slot in the direction of the fiber flow, which commences at the immediate vicinity of the front roller nipping line and ends in the region of the delivery nipping line. This creates an air current through the lattice apron via the slot towards the inside of the profile tube. The compacting of the fiber strand will start at the edge of this slot. The fibers follow the outer edge of this suction slot and at the same time they perform a lateral rolling motion. By the law of vectorial addition of speed, the speed of the portion of fibres along the edge (shown in Figure 6) will increase. This increase in speed of the portion of fibre moving along the downstream edge causes the fibres to be gently stretched. Fiber will be unable to cross the edge of the slot and will align itself closely to fibre. Thus a fibre bundle is transformed into a bundle where the fibres are perfectly 
parallel and close to each other [11]. The bigger diameter of the delivery top roller compared to the diameter of the front top roller creates a tension in longitudinal direction during the condensing process. The consequence of this tension causes the curved fibres to straighten [19]. The suction slot can be arranged at an angle to the direction of fiber flow, especially when processing short fibers. This ensures that the fiber ends are well bound into the strand during transportation in condensing zone. It also creates a transverse force on the band of fibers so that the fiber ends are closely embedded into the fiber assembly [15]. Recently SUESSEN has introduced D-Type slot compact system for producing carded compact yarn [20].

\section{3) CompACT3 by Zinser}

This System has a perforated apron over stationary hollow bodies subjected to negative pressure situated just after the 3 over 3 drafting arrangement (shown in Figure 7(a)). These hollow bodies are provided with straight slots in the direction of apron movement. The perforated apron has pores in the middle and the forms of these pores are in the order elliptical pores followed by circular ones (pearl-necklace fashion). Diameter of hole does not suck in the individual fibres and the holes distance, which allows a sufficient fixing over the fibre length. The dimension of the holes diameter depends on the yarn count. The distance of the perforation holes is chosen so that the desire hairiness is still kept. The fibers emerging from this drafting system are taken by airflow, and condensed under suction on a perforated apron/belt surface (shown in Figure 7(b)) [21].
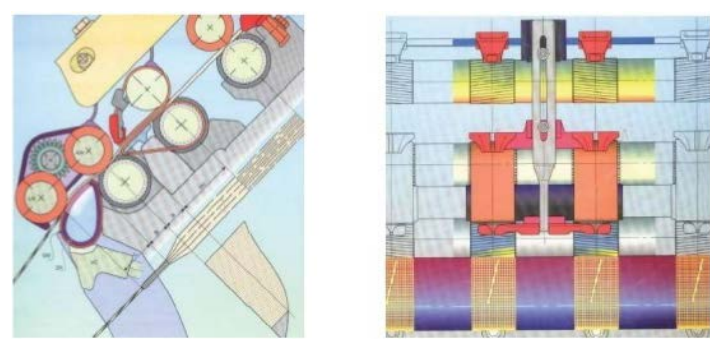

Figure 5. Structure of EliTe ${ }^{\circ}$ CompactSet (left) and suction slot (right).

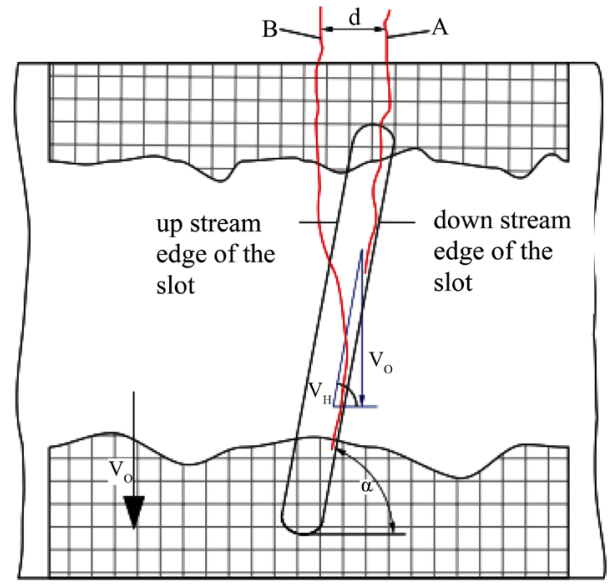

Figure 6. Fiber movement at suction slot [11]. 


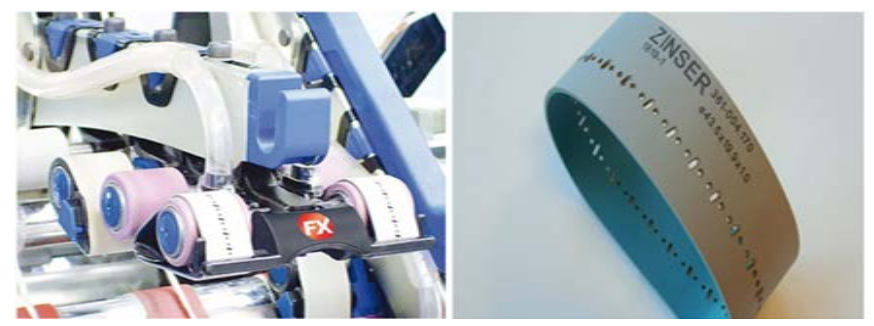

(a)

Figure 7. (a) The centrepiece of Zinser Impact FX \& (b) Compacting apron [22].

\section{4) Cognetex}

Cognetex S.p.A., Italy, exhibited its Com $4^{\infty}$ wool system, which is a long-staple adaptation of the Rieter Com4 system. The major changes made accommodate much longer fibers, achieved by utilizing angled balloon rollers (shown in Figure 8(a)) as the front rollers in the compacting zone [23].

\subsubsection{Mechanical Compact System}

The power required to produce air suction is substantial, the pneumatic compacting devices are expensive, and may require elaborate maintenance. As a result, the concept of mechanical compacting is economical solution for producing compact yarn.

\section{1) Officine guadino mechanical CSS}

This consists of an additional smooth bottom front roller and an angled top roller (shown in Figure 8(b)). These rollers run at a slightly slower speed than the front drafting rollers and this "negative" draft, coupled with the offset top roll, creates false twist which compacts the drafted strand as it issues from the compacting zone [24] [25].

\section{2) COMPACTeasy}

The COMPACTeasy device consists of the retainer holding the front top roller and the smaller COMPACTeasy Roller. The easy-Spring is pressing the COMPACTeasy Roller onto the bottom roller. Between the two top rollers there is the Compactor with the y-channel and the preceding Pin. The Compactor is pressed against the bottom roller by the Compactor spring with a low spring force, thus causing considerably less wear on the Compactor than magnetically loaded compacting elements. The y-channel (shown in Figure 9) permits double compacting, because mechanical compacting is effected twice by the special shape of the channel and the S-shaped flow of the fiber strand in the channel. This more intensive compacting compared to other mechanical compacting systems has a positive effect on the yarn parameters [26].

\section{3) Magnetic mechanical compacting system}

Another add-on type compacting system developed by Rotorcraft (a Swiss company) is RoCoS, the Rotorcraft Compact Spinning System, works without air suction and uses magnetic mechanical principles only. In Figure 10, above the clamping line A, a normal ring spinning drafting system is existed. After clamping line A the fibres are guided into the compacting slit-called trumpet of 
the compactor. Inside the compacting slit, the fibres are compacted mechanically. The magnetic compactor is pressed against the bottom roller without any clearance against it due to the magnetic force created by the magnetic part on the edge of compactor, thus forming an enclosed compression chamber in the slot. Inside this compact slot, the fibers are compacted mechanically. After the fibers have been compacted, they pass the clamping line B. The twist coming from the ring and traveller will directly translate into the fibres and solidify the compacted state. No twist and draft between line A and B [10]. In addition, Rocos compacting system is more effective in spinning coarser yarns rather than finer yarns [27].

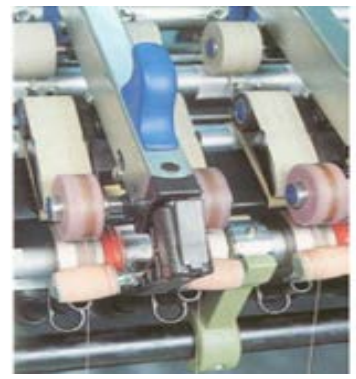

(a)

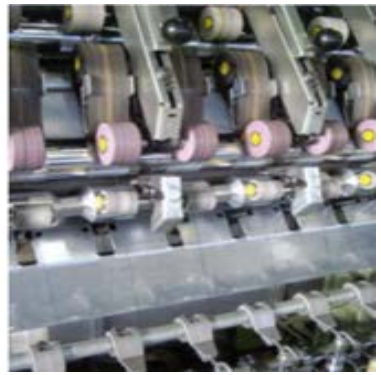

(b)

Figure 8. (a) Cognetex Com $4^{\circledR}$ wool system \& (b) Officine Guadino mechanical compacting system [24].
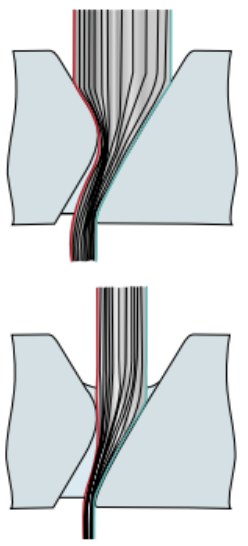

Figure 9. Y-channel in COMPACTeasy system [26].

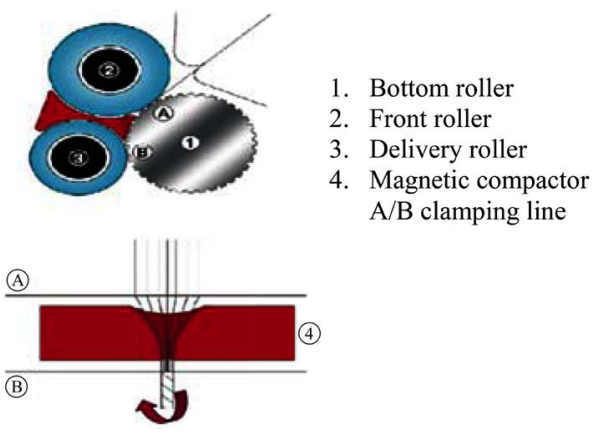

Figure 10. Major components of RoCoS unit [10]. 


\subsection{Jetring (Air-Plus Ring Tandem) Spinning System}

This system is based on the placement of the air nozzles used in the air-jet spinning system between the output system of the conventional ring spinning system and the yarn guide system, called jetring or nozzle ring (shown in Figure 11). Air is fed into the air nozzle used in the jetring system at a certain pressure value. Compressed air creates a rotating air vortex in the nozzle. By causing interfiber entanglements in a false twist spinning action, the air vortex ensures that the fiber ends that protrude outward from the yarn body are wound up in the yarn body, thereby reducing yarn hairiness.

In Jetring yarn production, a designed supporting device was first mounted on the spinning systems to enable nozzle usage. Many researchers have indicated that Jetring yarns have lower hairiness compared to that of conventional ring spun yarns [29] [30] [31]. A.P.S Sawhney et al. mentioned that the tandem spun yam clearly looks more compact, uniform, and (subjectively) less hairy than the conventional ring spun yam [32].

\subsection{Compact-Jet Yarn Spinning System}

To combine the compact spinning system and air nozzle, the nozzle was positioned between the exit of the compact spinning unit and yarn guide, and then Compact-jet yarns were produced. It is aimed to gather the advantages of the jetring and compact spinning systems. The compact-jet yarn is first loosened to some extent due to swirling air flow or false untwisting, which is the opposite direction to yarn twisting. Then it is tightened up again through the nozzle in terms of the false twisting, as mentioned for jetring yarns. This untwisting and twisting case contributes wrapping of the protruding hairs on to the yarn body, while swirling air flow does not cause any loss or additional twist in the yarn [33]. Compact-jet yarns have significantly lower hairiness values than ring and compact yarns [34].

\subsection{Siro Spinning System}

The SiroSPUN ${ }^{\text {ta }}$ process adapted some of the self-twist discoveries of CSIRO to the ring spinning technology of the worsted system, and combined spinning and doubling in the one operation. In this process, two rovings are led in parallel through the drafting system, separated by two specially developed condensers, and drafted separately (shown in Figure 12). The twist is introduced as for a normal single yarn by means of ring and traveller. The drafted roving strands at the exit from the drafting system, with some twist being produced in the individual strands right up to the nip point, are combined producing a twofold-like yarn (shown in Figure 13). Many researchers have reported that hairiness has been reduced significantly in siro spinning system [35] [36].

\subsection{Siro-Jet Spinning System}

The spinning system, which was based on a nozzle attachment to the sirospun 
spinning system, was named the siro-jet. The siro-jet spinning system improves the hairiness by up to $40 \%$ in comparison to the sirospun system as found in Jetring and Compact-jet spinning systems [37] [38] [39].

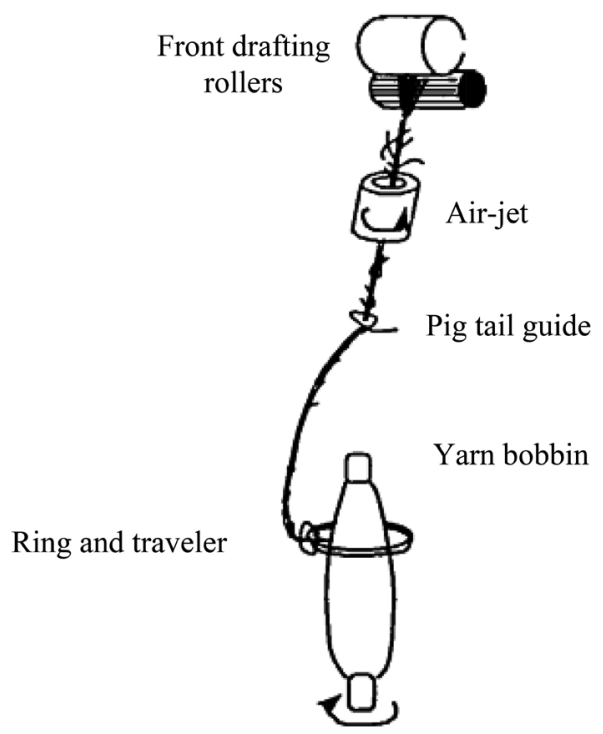

Figure 11. The Jet-Ring spinning system [28].

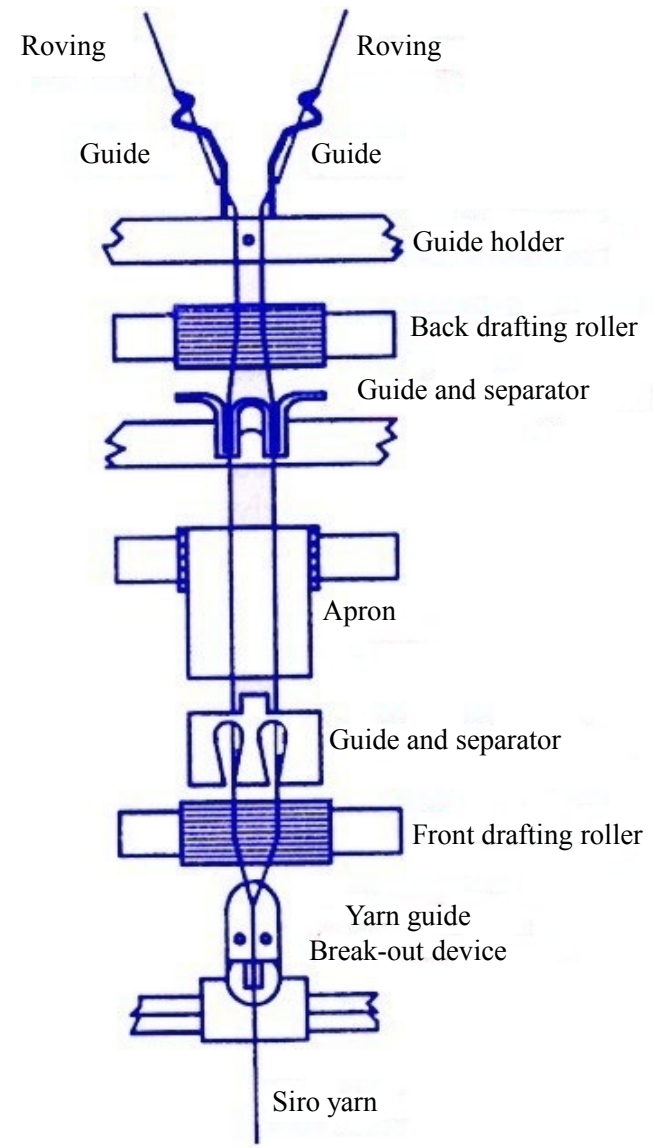

Figure 12. Siro spinning components. 


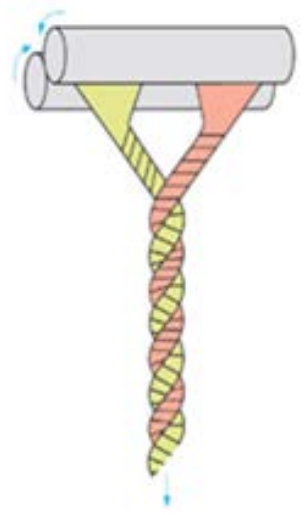

Figure 13. Spinning triangle formation at Siro-spinning system.

\subsection{Compact Siro Spinning}

The compact-Siro spun yarn incorporated the advantages of compact and Siro yarns [40]. It is conducted on a compact ring frame by simultaneously feeding two rovings, and incorporates the features of both Compact and Siro-spinning systems. Many researchers have mentioned compact-siro yarn (shown in Figure 14(a)) shows less hairiness in comparison to Siro yarn (shown in Figure 14(b)) [41] [42]. Spinning triangle (ST) of compact-siro spinning system has been shown in Figure 15.

\subsection{Solo Spinning System}

Firstly, a drafted strand enters the nip of a Solospun roller (shown in Figure 16(a)), which has a lot of small grooves that divide the drafted strand into two or three (even four) substrands; second, a primary twist is individually given to those substrands before they leave the Solospun roller, where several smaller twist triangles are produced, third, after coming from the Solospun roller, all substrands are twisted into a Solospun yarn by a final twist (shown in Figure 16(b)). This special twisting mechanism of Solospun entangles a lot of hairs into the yarn body, so the hairiness of Solospun yarns is reduced, especially for long hairs [44]. R. Ghasemi et al. reported Solospun roller in the worsted Sirospun spinning system significantly improves worsted blended wool/polyester yarn hairiness [45].

\subsection{Siro-Solo Spinning System}

The Solo-Siro spinning system is a new system which can produce a distinctive yarn structure by combining Solo and Siro spun processes [47].

\subsection{Pro-Spin Technology}

ProSPIN technology is based on bifurcation of a roving, feeded into a unit installed on a ring yarn machine, by means of a compactor at the outlet of drawing system and confluence of two groups of fiber compactly flowing out in two lines in a manner to form the yarn by taking the twist originating from ring-ring tra- 
veller system.

ProSPIN system (shown in Figure 17) is designed for the production of carded and combed yarns within the range of medium and medium-coarse counts. Compaction of masses (especially carded) containing fibers exceeding a certain number in the cross-section by using the existing compact spinning systems, fails to achieve the required success due to either geometrical reasons or excessive consumption of air. ProSPIN, eliminates such dissatisfaction by bisecting the fiber mass in a controlled manner followed by a separate compaction [48].
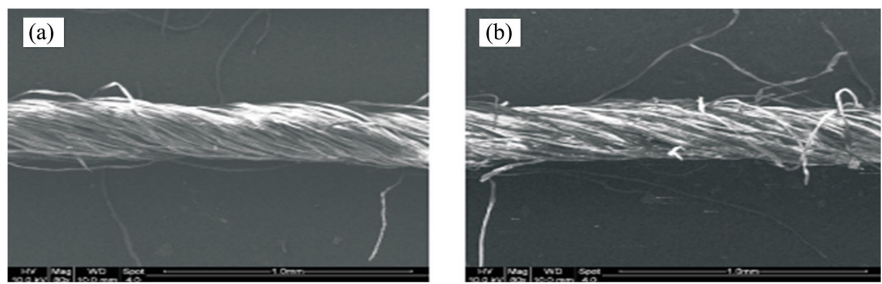

Figure 14. Image of (a) Compact-siro and (b) Siro-spun yarn [41].
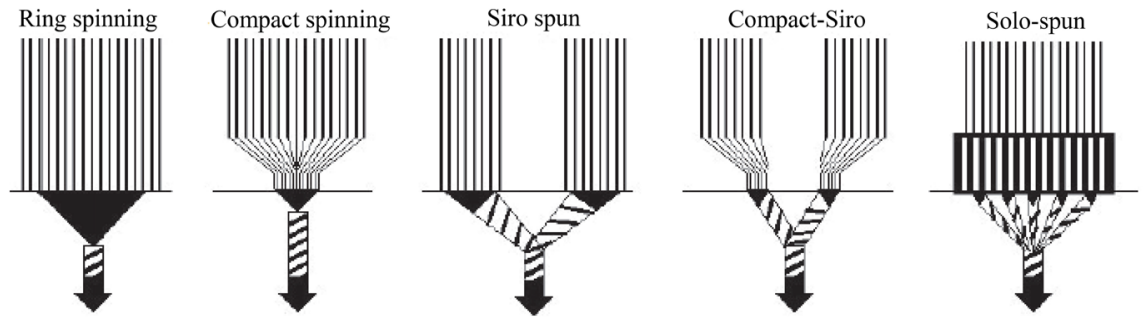

Figure 15. Spinning triangle in different spinning systems [43].

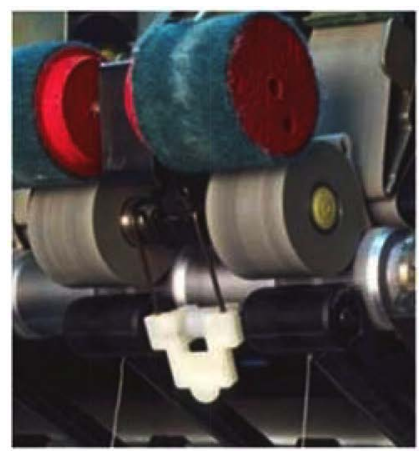

(a)

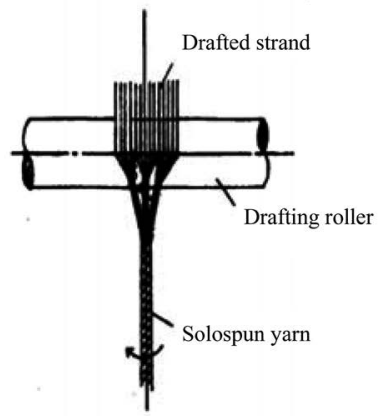

(b)

Figure 16. (a) Solospun Components \& (b) ST of Solospun [44] [46].
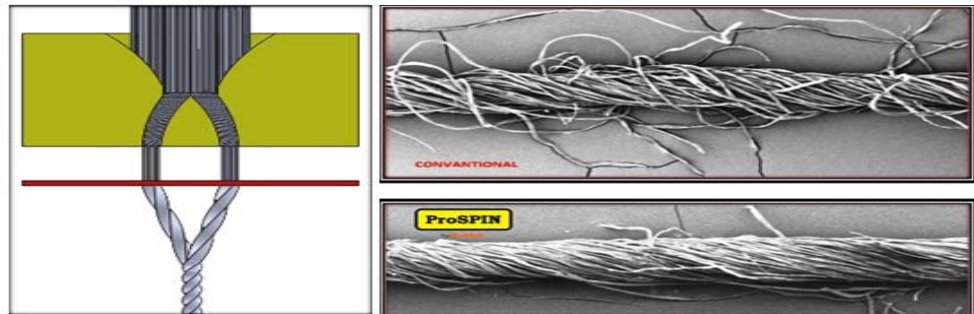

Figure 17. ST at ProSPIN technology [48]. 


\subsection{Nu-Torque Spinning}

Figure 18(a) shows the Nu-Torque ${ }^{\mathrm{ma}}$ spinning system installed in a spinning machine. With a false-twister installed between the front roller and the yarn guide, the yarn strength at the ST zone can be enhanced. The amount of false twist is given by the ratio of the pin rotational speed to yarn delivery speed. In ST zone, the extreme tension variation enlarged fiber migration. Nu-torque yarn spinning, higher twisting density in ST zone renders most fibers close to yarn center and altering radical position in the yarn with high amplitude (shown in Figure 18(b)); this is beneficial for improving yarn strength and hairiness [50].

\subsection{Offset Spinning System}

Offset spinning is a simple geometric modification of the ST for producing yarns with reduced hairiness (Shown in Figure 19). Fibers from both edges of the ST undergo significant change in their wrapping behavior depending on the direction of offset. Due to twist effect, the distribution of fiber tension within the triangle is asymmetrical and uneven in the practice of ring spinning. Conventionally in a Z-twist spinning process, fiber on the right side of the triangle always get twisted firstly while the left-hand edge fibers are slightly slack. This is called to be a pre-twisting process which effectively binds the fibres, while the left side fibres are comparatively less controlled. These cause an asymmetric fiber distribution in ST [51].

\subsubsection{Mismatch Spinning}

With the left diagonal arrangement, the yarn emerging from a drafting unit is taken up by an adjacent bobbin to the left of the drafting unit, instead of the bobbin directly below it (shown in Figure 20(i)). And vice versa for right diagonal arrangement. However, Thilagavathi reported that $50 \%$ yarn hairiness had been decreased with left diagonal path (LDP) for producing cotton coarser yarn [53].

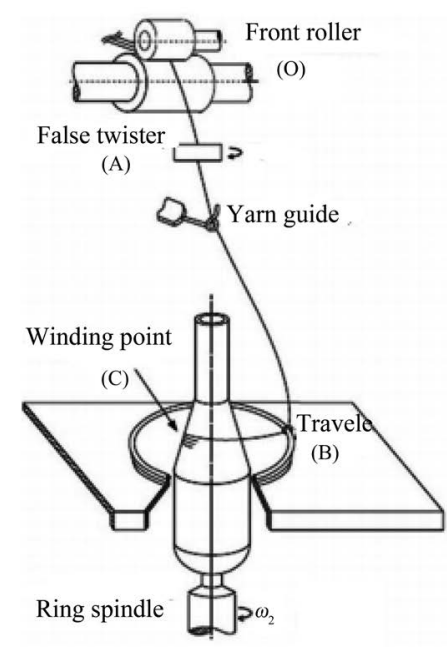

(a)

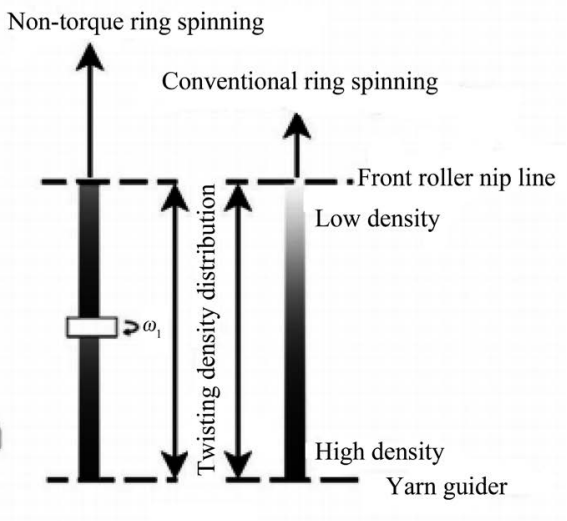

(b)

Figure 18. (a) Nu-torque spinning system and (b) Twisting density in ST [49]. 

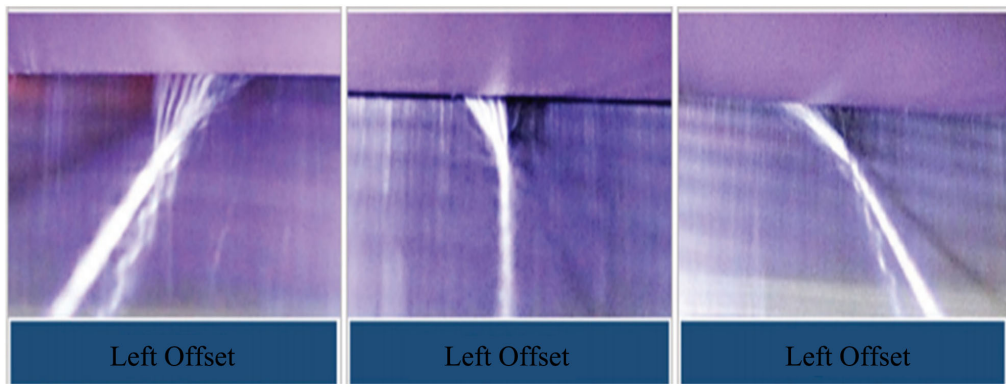

Figure 19. Imaging of the ST on an offset ring spinning system [52].

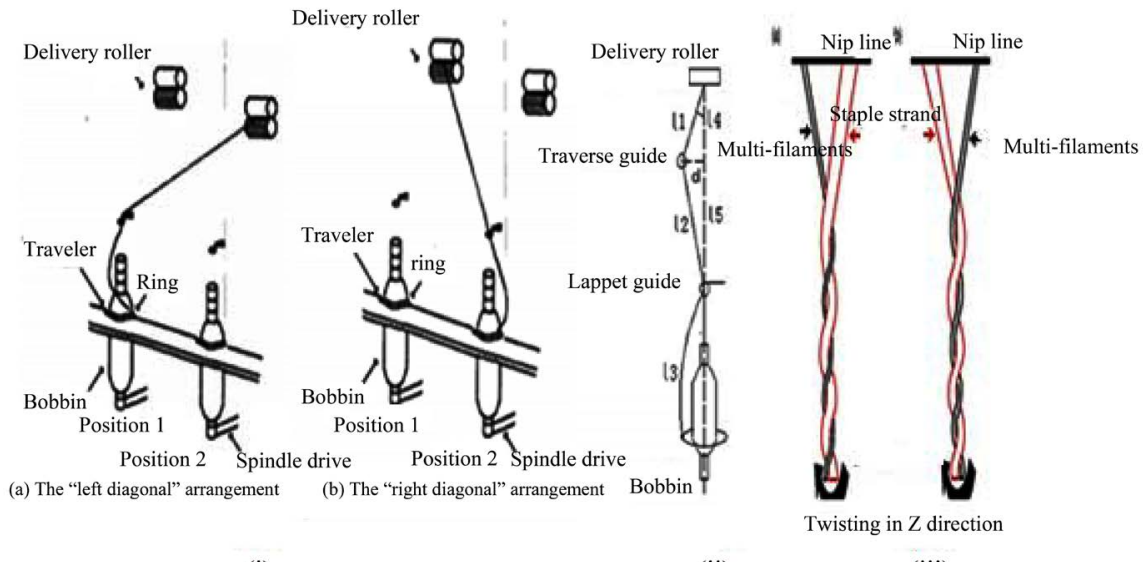

(i)

(ii)

(iii)

Figure 20. (i) Diagram of Mismatch Spinning, (ii) Modified Yarn Path System \& (iii) Sirofil spinning [54] [55] [56].

\subsubsection{Left Offset Spinning}

Studies by Xia et al. and Thilagavathi et al. supported the use of left offset spinning (shown in Figure 20(ii)). Their work proposed that the left diagonal path reduced the distance travelled by the uncontrolled fibers on the left-hand side of the spinning triangle to reach the convergence point, which leads to better fiber incorporation, while fibers on the right-hand side are controlled by the pre-twist [57].

\subsubsection{Right Offset Spinning}

With right diagonal arrangement, there is an increased concentration of fibers in the right hand side of skew triangle due to the increased pre-twisting of fibers. As a result, the pre-twisting effectively binds the fibers into the bulk of the yam structure, thus reducing yam hairiness. Charanpreet Singh et al \& Tingting Wu et al studied the offset spinning and reported that a right offset is effective in reducing hairiness for a Z-twist yarn while Left offset deteriorates hairiness results. An opposite effect is observed when the twist direction is changed. They explained that the right-hand edge position of pre-twist during left offset spinning causes slackness and delayed incorporation of left-hand edge fibers, which ultimately occupy the peripheral surface layers of the yarn, leading to increased hairiness [52]. 


\subsubsection{Sirofil Spinning System}

Sirofil spinning (shown in Figure 20(iii)) grew out of siro-spinning via replacing one siro-component with strong multifilaments [58]. When the left siro component is substituted by multifilaments, the staple strand on the right is twisting just in a "left diagonal" (LDP). On the contrary, if the right siro component is substituted by multifilaments, the staple strand on the left is twisting just in a "right diagonal" path (RDP).

\subsection{Contact Spinning System}

A contact surface is applied to provide nip points to hold protruding hairs re-wrapping onto yarn stem in the yarn formation zone. To be exact, the twist density of input fiber strand is lower than that of the output strand (shown in Figure 21). Moreover, lower twist density spinning strand has a looser structure, which is beneficial for fiber ends wrapped into yarn body. As the twist density increases, spinning strand structure becomes more compact, which may help above wrapped fiber ends to be tightly fastened into or onto yarn stem.

The single static contact surface may be not enough to hold the yarn hairs firmly during the re-wrapping onto the yarn surface; therefore, a self-adjustable disk surface is added by Zhigang Xia et al. to enhance the force of holding yarn surface hairs (shown in Figure 22). If hairs wrap onto the yarn stem in a concentrated formation, the adjustable disk surface will perform a vertical upward motion (shown in Figure 23). Then, the friction force resisting the twists up-flowing to the front roller nip will be correspondingly decreased, prohibiting unexpected drawing of the excessive low twisted fiber strand between the front nip and the contact surfaces [59] [60].

\subsection{Pre-Twister Process}

Keyi Wang et al. compared this system with the conventional ring frame by mentioning a pre-twister and a holding roller added to the ring frame (shown in Figure 24). The respective ends of the core fibers are firmly held by the front roller and holding roller, the free leading ends would be wrapped on core fibers. With the entanglements by the free leading ends which are continuously controlled by the holding roller, the air vortex converts the drafted fibers into a partially strengthened and wrapped structure which produce lower level of yarn hairiness as well [61].

\subsection{Agent Aided Spinning System (AAS)}

The AAS is fixed on the yarn formation zone between the front roller nip and the yarn guide, as shown in Figure 25. Self-rotating cylinder connected with a speed governing motor has direct contact with the fibrous strand in the yarn formation zone and the lower part of the cylinder is submerged in the water. When the cylinder contacts the fibrous strand, the liquid water wets the surface of the fibrous strand. Generally, a liquid with less surface tension will possess better wet ability. The surface tension of cellulose fibers is $200 \mathrm{mN} / \mathrm{m}$; therefore, 
liquid water with a surface tension of $72 \mathrm{mN} / \mathrm{m}$ at $25^{\circ} \mathrm{C}$ has good wet ability on cellulose fibers. With good wet ability, the yarn hair protruding out of the yarn body (shown in figure Figure 26) can be attached to the yarn surface (shown in Figure 26(a)) through the adhesive force between the fibers and water, and the cohesion force of the liquid water (shown in Figure 26(b)). Although the cylinder impedes the twist propagation to some extent, the formation of the yarns is not affected. Adhered hairy fiber in yarn body is shown in Figure 26(c). In addition, only the outer layer of the fibrous strand touches the water and this water evaporates during the balloon process [62].

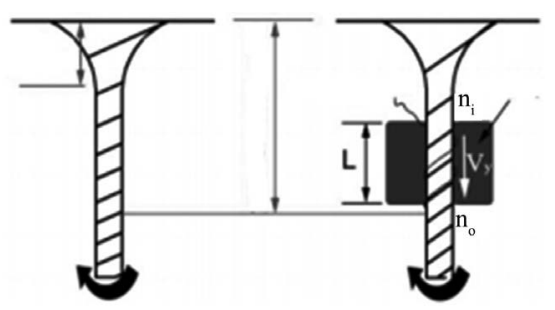

(a)

(b)

Figure 21. Twisting density in ST formed at contact spinning system [59].

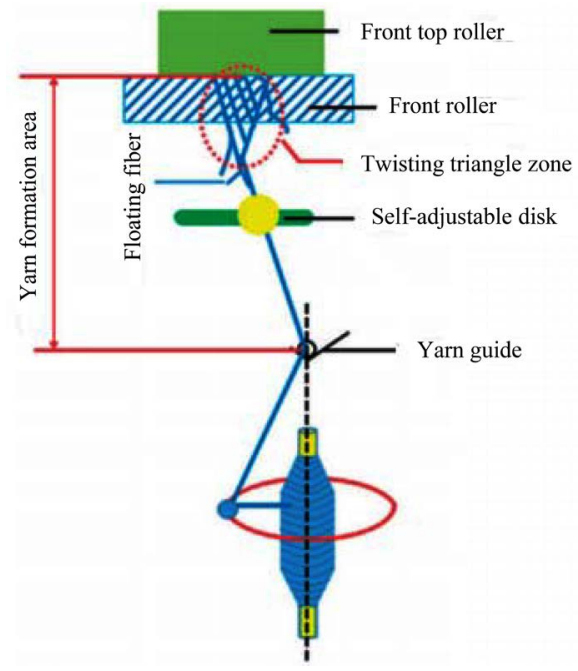

Figure 22. Self-adjustable Contact spinning System [60].

(a)

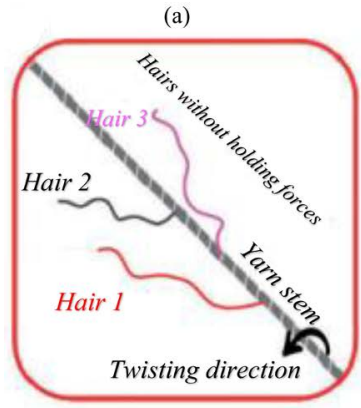

(b)

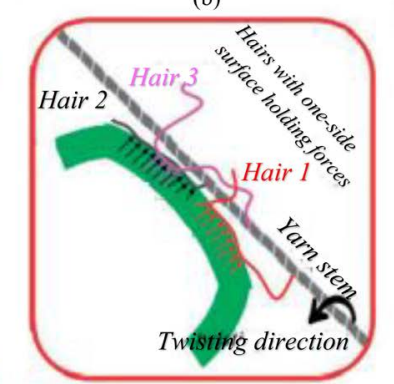

Normal forces of the contact surface exerting onto hair 1

Normal forces of the contact surface exerting onto hair 2

(c)

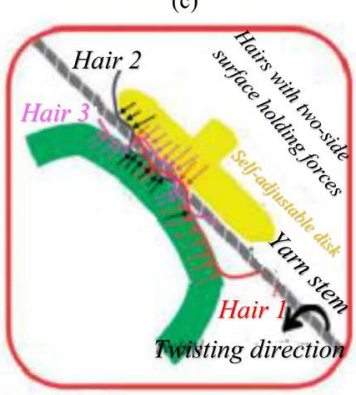

isting directio

- Normal forces of the contact surface exerting onto hair 3

Figure 23. Illustration of the enhancement of hair-holding forces [60]. 

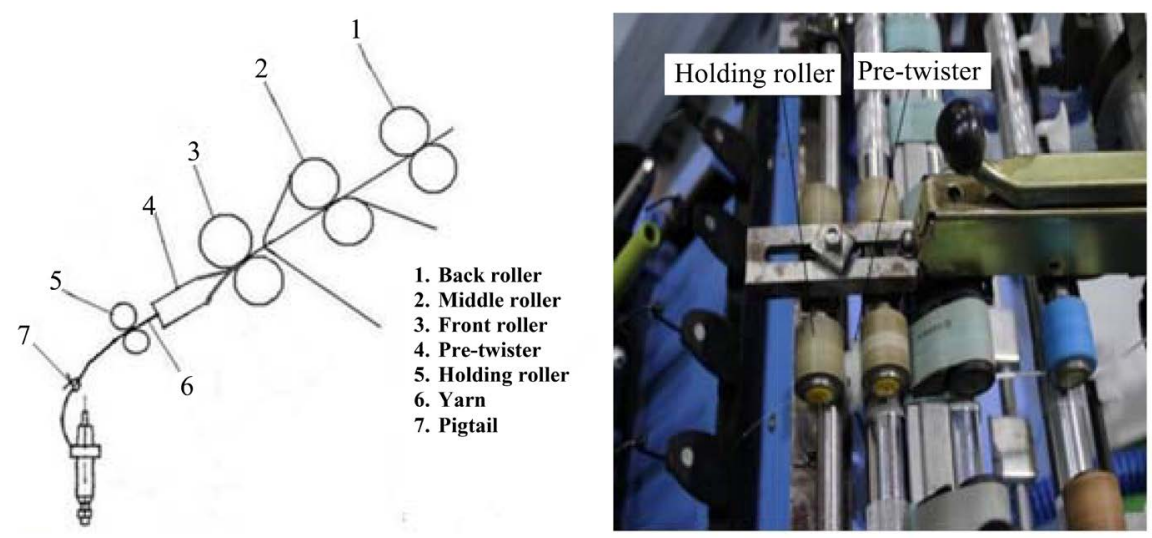

Figure 24. Pre-Twisted Ring Spinning System (left) Schematic diagram and (right) Modified system [61].

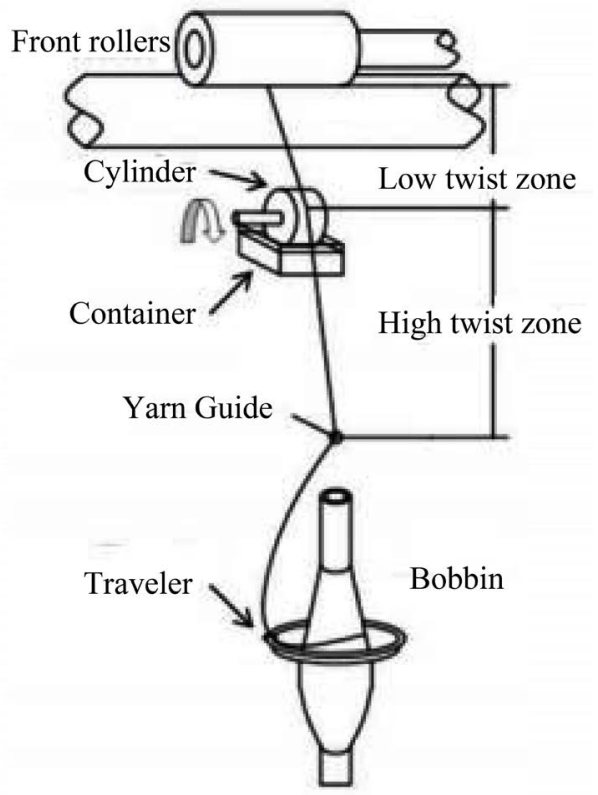

Figure 25. The sketch of agent-aided system on the ring frame [62].

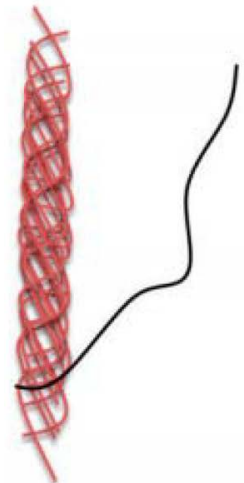

(a)

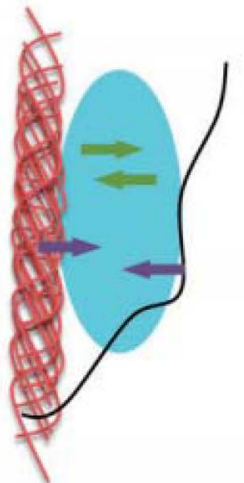

(b)

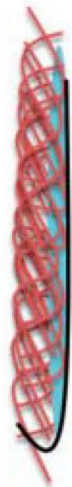

$\sim^{\text {Yarn hair }}$

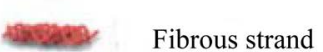

Liquid water

$\Rightarrow$ Cohesion force

Adhesion force

(c)

Figure 26. A schematic illustration of the adhesion theory for the agent-aided system [62]. 


\section{Conclusion}

The quality of ring spun yarn in terms of strength and elongation has been used as the benchmark for yarns spun on other spinning systems but traditional ring spinning system is associated with several limitations, one of which is yarn hairiness. However, the dimensions of the spinning triangle (ST) and the distribution of fibers in it have a decisive influence on yarn hairiness. The ST resists the marginal fibers from being fully integrated into the ring spun yarn structure. Various studies based on the relationships between the spinning triangle and yarn hairiness have been performed by many researchers. Compact or condensed spinning is the most remarkable modification of ring frame to reduce yarn hairiness. The compact spinning systems reduce the length and width of the spinning triangle (ST) to a minimum or even eliminate to achieve lower level of hairiness in short and long staple yarn. The other ST based modification concept such as jet ring, siro, solo spinning and also their hybrid systems (i.e., compact-jet, siro-jet, siro-solo and compact-siro) have been attracted a lot of attention for their improved performances in term of yarn hairiness. Some researchers have argued that offset spinning system (i.e., modified yarn path) has lower level of yarn hairiness compared to conventional ring frame. Nu-torque spinning works on the basis of online twist density distribution by installing a false twisting assembly in the path of yarn and affects the fibers in ST. Contact spinning as well as agent aided spinning system can rewrap the protruding fibers that have been escaped from ST. Nowaday's many companies offer their retrofitted components (add-on type) to be fitted with conventional ring frame for controlling the geometry of spinning triangle in order to obtain lower level of yarn hairiness. It is expected that the future belongs to these types of modified ring frame.

\section{Conflicts of Interest}

The authors declare no conflicts of interest regarding the publication of this paper.

\section{References}

[1] Özdil, N., Özdoğan, E., Demirel, A. and Öktem, T. (2005) A Comparative Study of the Characteristics of Compact Yarn-Based Knitted Fabrics. Fibers \& Textiles in Eastern Europe, 13, 39-43.

[2] Wang, L.J. and Wang, X.G. (2007) A Controlled Experiment on Yarn Hairiness and Fabric Pilling, Rafael Beltran. Textile Research Journal, 77, 179-183. https://doi.org/10.1177/0040517507079409

[3] Sun, Y.Y., Pan, R.R., Zhou, J. and Gao, W.D. (2017) Analysis of Detectable Angles of Yarn Hairiness in Optical Measurements. Textile Research Journal, 87, 1297 1307. https://doi.org/10.1177/0040517516651108

[4] Furferi, R., Governi, L. and Volpe, Y. (2012) A Novel Method for Ring Spinning Performance Evaluation Based on Computer Aided Analysis of Yarn Geometry. International Journal of Mechanics, 6, 212-221. 
[5] Alagirusamy, R. and Das, A. (2010) Technical Textile Yarns: Industrial and Medical Applications. Woodhead Publishing Limited and CRC Press, Boca Raton.

[6] Yilmaz, D. and Usal, M.R. (2012) Effect of Nozzle Structural Parameters on Hairiness of Compact-Jet Yarns. Journal of Engineered Fibers and Fabrics, 7, 56-65. https://doi.org/10.1177/155892501200700209

[7] Murugesan, M., Senthilkumar, T. and Nayar, R.C. (2017) Prediction of the Spinning Triangle Height in Ring Frame Using Artificial Neural Networks. IOSR Journal of Polymer and Textile Engineering, 4, 1-7. https://doi.org/10.9790/019X-04030107

[8] Spinnovation_No._29, May 2014. The Magazine for Spinning Mill. https://www.graf-companies.com/fileadmin/spinnovation/Spinnovation_No._29_-Web.pdf

[9] Ahmad, M.M. (2009) Future Belongs to Compact Spinning. http://www.indiantextilejournal.com/articles/FAdetails.asp?id=2249

[10] Oerlikon Textile Components (2008) Product Presentation Texparts ${ }^{\circledast}$ RoCoS. http://www.flatexsp.com.br/product_presentation_rocos_v9_2008-11-081.pdf

[11] Spinnovation_No._24, July 2008. The Magazine for Spinning Mill.

[12] Wang, K.Y., Xue, W.L. and Cheng, L.D. (2018) Nozzle Based Compact Spinning. Journal of Textile Engineering \& Fashion Technology, 4, 137-139. https://doi.org/10.15406/jteft.2018.04.00136

[13] Liu, X.J., Zhang, H. and Su, X.Z. (2016) Comparative Analysis on Pneumatic Compact Spinning Systems. International Journal of Clothing Science and Technology, 28, 400-419.

[14] Altas, S. and Kadoğlu, H. (2012) Comparison of Conventional Ring, Mechanical Compact and Pneumatic Compact Yarn Spinning Systems. Journal of Engineered Fibers and Fabrics, 7, 87-100. https://doi.org/10.1177/155892501200700110

[15] El Mogahzy, Y. (2004) Developments in Textile Technology: ITMA 2003 Review Part II: Spinning Machinery. Beltwide Cotton Conferences, San Antonio, 5-9 January 2004

[16] Liu, X.J., Liu, W.L., Zhang, H. and Su, X.Z. (2015) Research on Pneumatic Compact Spun Yarn Quality. The Journal of The Textile Institute, 106, 431-442.

https://doi.org/10.1080/00405000.2014.925198

[17] Rieter-k48-Brochure.

https://www.rieter.com/fileadmin/user_upload/products/documents/systems/end-s pinning/rieter-k48-brochure-3237-v1-89652-en.pdf

[18] Alagirusamy, R. and Das, A. (2010) Advances in Yarn Spinning and Texturising. Woodhead Publishing Limited and CRC Press, Boca Raton.

[19] Kumar, A., Ishtiaque, S.M. and Salhotra, K.R. (2003) Compact Spinning: A Critical Review. ASME International Mechanical Engineering Congress \& Exposition, Washington DC, 16-21 November 2003, IMECE2003-44321.

[20] Loganathan, R., Mallyah, M. and Ramachandran, T. (2009) Influence of D-Type Slot Compact System on Migration Properties of the Carded Compact Yarn. Journal of Engineered Fibers and Fabrics, 4, 7-13. https://doi.org/10.1177/155892500900400403

[21] CompACT ${ }^{3}$ - Road to a New Ring Spinning Dimension. Pakistan Textile Journal. http://ptj.com.pk/Web\%202003/5-2003/zinser.htm

[22] Textile Excellence (2018) Impact FX for Spinning. https://www.textileexcellence.com/news/machinery-and-technology/saurer-ushers-i n-gennext-impact-fx-for-spinning/ 
[23] https://www.textileworld.com/textile-world/features/2004/01/itma-2003-spinning-t echnology

[24] Oxenham, W. (2003) Spinning Machines at ITMA'03. Journal of Textile and Apparel, Technology and Management, 3, 1-6.

[25] https://www.woolwise.com/wp-content/uploads/2017/07/Wool-482-582-08-T-15.pdf

[26] Suessen-Compacteasy-Brochure. https://www.rieter.com/fileadmin/user_upload/products/documents/systems/end-s pinning/suessen-compacteasy-brochure-93211-en.pdf

[27] Altas, S. and Kadoğlu, H. (2012) Comparison of Conventional Ring, Mechanical Compact and Pneumatic Compact Yarn Spinning Systems. Journal of Engineered Fibers and Fabrics, 7, 87-100. https://doi.org/10.1177/155892501200700110

[28] Wang, X.G. (1997) Studies of JetRing Spinning Part I: Reducing Yarn Hairiness with the JetRing. Textile Research Journal, 67, 253-258. https://doi.org/10.1177/004051759706700403

[29] Cheng, K.P.S. and Li, C.L. (2002) JetRing Spinning and Its Influence on Yarn Hairiness. Textile Research Journal, 72, 1079-1082. https://doi.org/10.1177/004051750207201207

[30] Zeng, Y.C. and Yu, C.W. (2004) Numerical and Experimental Study on Reducing Yarn Hairiness with the JetRing and JetWind. Textile Research Journal, 74, 222-226. https://doi.org/10.1177/004051750407400306

[31] Rengasamy, R.S., Kothari, V.K., Patnaik, A. and Punekar, H. (2006) Airflow Simulation in Nozzle for Hairiness Reduction of Ring Spun Yarns. Part I: Influence of Airflow Direction, Nozzle Distance and Air Pressure. Journal of Textile Institute, 97, 89-96. https://doi.org/10.1533/joti.2005.0218

[32] Sawhney, A.P.S., et al. (1997) Air and Ring Combination in Tandem Spinning. Textile Research Journal, 67, 217-223. https://doi.org/10.1177/004051759706700310

[33] Yilmaz, D. and Usal, M.R. (2011) A Comparison of Compact-Jet, Compact, and Conventional Ring-Spun Yarns. Textile Research Journal, 81, 459-470. https://doi.org/10.1177/0040517510385174

[34] Yilmaz, D. and Usal, M.R. (2013) Investigation of Yarn Properties of Modified Yarn Spinning Systems with Air Nozzle Attachment. Fibers \& Textiles in Eastern Europe, 2, 43-50.

[35] Liu, S.Q., Dai, J.M., Jia, H.S., Liu, X.G. and Xu, B.S. (2011) Effect of Siro-Spun Processing Parameters on Properties of 55/45 Flax/Cotton Blended Yarn. Advanced Materials Research, 331, 502-511. https://doi.org/10.4028/www.scientific.net/AMR.331.502

[36] Çelik, P., Üte, T.B. and Kadoğlu, H. (2012) Comparative Analysis of the Physical Properties of the Fabrics Knitted with Sirospun Yarn and Ring Spun Yarn Produced by Short and Long Staple Fibers. Tekstil ve Konfeksiyon, 22, 324-331.

[37] Yilmaz, D. and Usal, M.R. (2013) Improvement in Yarn Hairiness by the Siro-Jet Spinning Method. Textile Research Journal, 83, 1081-1100. https://doi.org/10.1177/0040517512471748

[38] Nejada, S., Shaikhzadeh Najar, S. and Hasani, H. (2011) Application of Air-Jet Nozzle in Short Staple Siro Spinning System. The Journal of the Textile Institute, 102, 14-18. https://doi.org/10.1080/00405000903415322

[39] Ylmaz, D. and Usal, M.R. (2012) A Study on Siro-Jet Spinning System. Fibers and Polymers, 13, 1359-1367. https://doi.org/10.1007/s12221-012-1359-2

[40] Lu, Y.Z., Wang, Y. and Gao, W.D. (2019) Strength Distribution Superiority of 
Compact-Siro Spun Yarn. Journal of Engineered Fibers and Fabrics, 14.

[41] Su, X.Z., Gao, W.D., Liu, X.J., Xie, C.P. and Xu, B.J. (2015) Research on the Compact-Siro Spun Yarn Structure. FIBRES \& TEXTILES in Eastern Europe, 3, 54-57. https://doi.org/10.5604/12303666.1152447

[42] Regar, M.L., Sinha, S.K. and Chattopadhyay, R. (2019) Comparative Assessment of Eli-Twist and Siro Yarn Made from Polyester and Its Blend with Cotton. Indian Journal of Fibre \& Textile Research, 44, 299-305.

[43] Buharali, G. and Omeroglu, S. (2019) Comparative Study on Carded Cotton Yarn Properties Produced by the Conventional Ring and New Modified Ring Spinning System. Fibers \& Textiles in Eastern Europe, 2, 45-51. https://doi.org/10.5604/01.3001.0012.9986

[44] Cheng, L.D., Fu, P.H. and Yu, X.Y. (2004) Relationship between Hairiness and the Twisting Principles of Solospun and Ring Spun Yarns. Textile Research Journal, 74, 763-766. https://doi.org/10.1177/004051750407400903

[45] Ghasemi, R., Mozafari-Dana, R., Etrati, S.M. and Shaikhzadeh Najar, S. (2008) Comparing the Physical Properties of Produced Sirospun and New Hybrid Solo-Siro Spun Blend Wool/Polyester Worsted Yarns. Fibers \& Textiles in Eastern Europe, 16, 24-27.

[46] https://www.woolwise.com/wp-content/uploads/2017/05/04.4-Fine-wool-yarn-spin ning-Notes.pdf

[47] Soltani, P. and Johari, M.S. (2013) Effect of Using the New Solo-Siro Spun Process on Structural and Mechanical Properties of Yarns. Fibers \& Textiles in Eastern Europe, 3, 51-54.

[48] http://www.prospin.com.tr/en/prospin-technology

[49] Xia, Z.G. and Xu, W.L. (2013) A Review of Ring Staple Yarn Spinning Method Development and Its Trend Prediction. Journal of Natural Fibers, 10, 62-81. https://doi.org/10.1080/15440478.2012.763218

[50] Yang, K., Tao, X.M., Xu, B.G. and Lam, J. (2007) Structure and Properties of Low Twist Short-Staple Singles Ring Spun Yarns. Textile Research Journal, 77, 675-685. https://doi.org/10.1177/0040517507080545

[51] Wu, T.T., Xie, C.P., Su, X.Z., Liu, X.J. and Huang, B. (2011) A Modified Ring Spinning System with Various Diagonal Yarn Path Offsets. Procedia Engineering, 18, 1-6. https://doi.org/10.1016/j.proeng.2011.11.001

[52] Singh, C., Gordon, S. and Wang, X.G. (2018) The Mechanism of Hairiness Reduction in Offset Ring Spinning with a Diagonal Yarn Path. Textile Research Journal, 89, 1546-1556. https://doi.org/10.1177/0040517518775915

[53] Thilagavathi, G., Gukanathan, G. and Munusamy, B. (2005) Yarn Hairiness Controlled by Modified Yarn Path in Cotton Ring Spinning. Indian Journal of Fibre \& Textile Research, 30, 295-301.

[54] Wang, X.G. and Chang, L.L. (2003) Reducing Yarn Hairiness with a Modified Yam Path in Worsted Ring Spinning. Textile Research Journal, 73, 327-332. https://doi.org/10.1177/004051750307300409

[55] Wu, T.T., Xie, C.P., Su, X.Z., Liu, X.J. and Huang, B. (2011) A Modified Ring Spinning System with Various Diagonal Yarn Path Offsets. Procedia Engineering, 18, 1-6. https://doi.org/10.1016/j.proeng.2011.11.001

[56] Xia, Z.G., Liu, H., Huang, J.J., Gu, S.J. and Xu, W.L. (2015) A Study on the Influence of a Surface-Contacting Spinning Strand on Yarn Appearance during Sirofil Spinning. Textile Research Journal, 85, 128-139. 
https://doi.org/10.1177/0040517514542863

[57] Thilagavathi, G., Udayakumar, D. and Sasikala, L. (2009) Yarn Hairiness Controlled by Various Left Diagonal Yarn Path Offsets by Modified Bottom Roller Flute Blocks in Ring Spinning. Indian Journal of Fibre \& Textile Research, 34, 328-332.

[58] Xia, Z., Wang, X., Ye, W., et al. (2012) Fiber Trapping Comparison of Embeddable and Locatable Spinning with Sirofil and Siro-Spinning with Flute Pipe Air Suction. Textile Research Journal, 82, 1255-1262. https://doi.org/10.1177/0040517512439918

[59] Xia, Z.G., Xu, W.L., Zhang, M., Qiu, W.B. and Feng, S.L. (2012) Reducing Ring Spun Yarn Hairiness via Spinning with a Contact Surface. Fibers and Polymers, 13, 670-674. https://doi.org/10.1007/s12221-012-0670-2

[60] Liu, K.S., Xia, Z.G., Xu, W.L., Hao, Y., Xu, Q.L., Jin, W.B. and Ni, J.L. (2018) Improving Spun Yarn Properties by Contacting the Spinning Strand with the Static Rod and Self-Adjustable Disk Surfaces. Textile Research Journal, 88, 800-811. https://doi.org/10.1177/0040517517716903

[61] Wang, K.Y., et al. (2018) A Numerical and Experimental Study on a Pre-Twisted Ring Spinning System. Polymers (Basel), 10, 671. https://doi.org/10.3390/polym10060671

[62] Li, P.Y., Guo, M.R., Sun, F.X. and Gao, W.D. (2019) Reducing Yarn Hairiness in Ring Spinning by an Agent-Aided System. Textile Research Journal, 89, 4438-4451. https://doi.org/10.1177/0040517519835769 